\title{
Temporal Lobe Pleomorphic Xanthoastrocytoma
}

National Cancer Institute

\section{Source}

National Cancer Institute. Temporal Lobe Pleomorphic Xanthoastrocytoma. NCI

Thesaurus. Code C156042.

A pleomorphic xanthoastrocytoma that arises from the temporal lobe of the brain. 